\title{
BER of Various Modulation Techniques Under Atmospheric Turbulences
}

\author{
Priyanka Bhardwaj, Aadi Jain, Manveen, Richita Kamal, Rishab Chittlangia
}

\begin{abstract}
Noise in the communication channel is well established to be a threat to digital bit transmission, resulting in many mistakes at the bit level. Different modulation methods are studied in terms of $B E R$, probability of error and SNR to better comprehend this. In the presence of specific levels of noise in the communication channel, this analysis yields an interesting conclusion that advises the employment of particular modulation methods. A comprehensive analysis of several modulation schemes has been considered. Those include On-Off Key modulation (OOK), Binary Phase Shift Key (BPSK), Quadrature Phase Shift Key (QPSK), Pulse Amplitude Modulation (PAM) and 8-Phase Shift Key (8-PSK). This analysis can aid in the selection of a modulation approach based on the channel condition.
\end{abstract}

Keywords: Optical Wireless Communication, Modulation Schemes, OOK, BPSK, QPSK, M-PAM, M-PSK, Turbulence, Log-Normal Distribution, Negative Exponential Distribution.

\section{INTRODUCTION}

$W_{\text {ith wireless multimedia communications gaining more }}$ popularity, there is an increased demand for high bit rates along with increased reliability and reduced bandwidth in a communication system. The OFDM is a digital modulation scheme that can support high speed communication and at the same, accommodates a greater number of users ensuring high spectral efficiency [1]. It is a multiplexing/multiple access scheme with many favourable features supporting next generation wireless systems [2].

The Optical Wireless System has a number of benefits, including a high data rate, built-in security, and low battery consumption. It has an unlicensed optical wavelength that allows communication up to several kilometres and can communicate between the ground and satellites [3, 4]. It employs line-of-sight communication, which is widely used in a variety of applications [5, 6]. Because of its lower power

Manuscript received on June 09, 2021.

Revised Manuscript received on June 17, 2021.

Manuscript published on June 30, 2021.

* Correspondence Author

Priyanka Bhardwaj*, Department of Electronics and Communication Engineering, ABES Engineering College, Ghaziabad (U.P), India. Email: priyanka.bhardwaj@abes.ac.in

Aadi Jain, Department of Electronics and Communication Engineering, Bharati Vidyapeeth's College of Engineering, New Delhi, India. Email: aadi521@gmail.com

Manveen, Department of Electronics and Communication Engineering, Bharati Vidyapeeth's College of Engineering, New Delhi, India. Email: manveenbangar@gmail.com

Richita Kamal, Department of Electronics and Communication Engineering, Bharati Vidyapeeth's College of Engineering, New Delhi, India. Email: richitakamal99@gmail.com

Rishab Chittlangia, Department of Electronics and Communication Engineering, Bharati Vidyapeeth's College of Engineering, New Delhi, India. Email: rishabchittlangia@gmail.com

(C) The Authors. Published by Blue Eyes Intelligence Engineering and Sciences Publication (BEIESP). This is an open access article under the CC BY-NC-ND license (http://creativecommons.org/licenses/by-nc-nd/4.0/) consumption, FSO systems do not interfere with other wireless communication channels. It satisfies the need for increased data rates while maintaining secure wireless connection. However, atmospheric turbulence and varied weather conditions such as rain, haze, smoke, fog, snow, and mist have an impact on this technology. Fog weather and atmospheric turbulence have a significant impact on the FSO link. The performance of optical wireless communication systems has been studied in the presence of air turbulence [7] by different modulation schemes and the findings helped to improve the performance of digital communication systems and enabled faster and relatively less error prone communication [8].

Under atmospheric and fog circumstances, this research investigates the performance of FSO links using various modulation techniques such as OOK, BPSK, QPSK, M-PAM, and M-PSK.

\section{BASIC MODULATION TECHNIQUES}

There are a variety of phase modulation methods that are suitable for FSO communication systems, as we all know. The SNR, bandwidth efficiency, and power efficiency under various modulation methods will be discussed in this part, although air turbulence will not be considered.

\section{A. On-Off Keying}

A binary one is represented by the presence of a carrier for a certain duration, while a binary zero is represented by the lack of a carrier for the same length. The OOK modulation technique is a frequently used direct detection approach in optical communication [9]. RZ and NRZ waveforms can be used for this modulation. The following formulae can be used to calculate the likelihood of error from an optical photodiode:

$$
\begin{aligned}
& B E R-N R Z O O K=\frac{1}{2} \operatorname{erfc}\left(\frac{1}{2 \sqrt{2}} \sqrt{S N R}\right) \\
& B E R-R Z O O K=0.5 \operatorname{erfc}(0.5 \sqrt{S N R})
\end{aligned}
$$

When OOK is more spectrally efficient than frequency-shift keying when using a regenerative receiver or a poorly designed super-heterodyne receiver, but it is more noise-prone[10].

\section{B. Binary Phase Shift Keying}

Binary Phase Shift Keying (BPSK) is a two-phase modulation method in which the carrier signal's 0s and 1s are represented by two separate phase states: $\theta=0^{\circ}$ for binary 1 and $\theta=180^{\circ}$ for binary $0[11]$.

Published By:

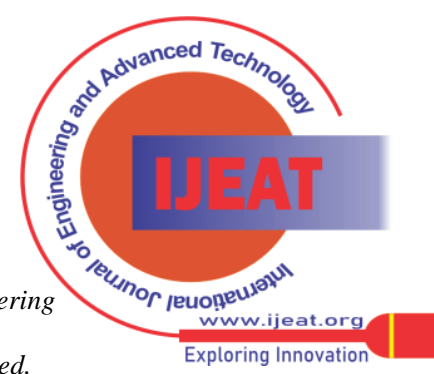


The coherent detection technique uses the BPSK modulation technology. The laser is always used as the carrier in optical communication [12].

There are two ways for demodulation: homodyne detection and heterodyne detection. In BPSK modulation, the phase shift is between 0 and 180 degrees. This technique's $\mathrm{BER}$ is given by the equation:

$$
B E R=1 / 2 \operatorname{erfc}(\sqrt{S N R}
$$

\section{Phase Shift Keying}

Two parallel connected QPSK modulators with SPDT switches, a power combiner, and 450 phase shifters make up the 8-PSK modulator's configuration. The amplitude and phase inaccuracy of an 8-PSK signal is exactly proportional to the phase shifter and elementary modulator's amplitude and phase accuracy $[13,14]$. For PSK, the BER is as follows:

$$
\mathbf{B E R}_{\mathrm{M}-\mathrm{PSK}}=\frac{1}{m} \operatorname{erfc}\left(\sqrt{\frac{m E b}{N o}} \sin \left(\frac{\Pi}{M}\right)\right)
$$

\section{Quadrature Phase Shift Keying}

Simulating two BPSK systems in tandem is equal to using a QPSK system. As a result, the bit error rate does not differ (BER).Because QPSK is made up of two BPSK orthogonal signals it might be considered a composite signal. As a result, each bit takes $\mathrm{Tb}$ seconds to complete, and the signals corresponding to the bits last for $\mathrm{Ts}=2 \mathrm{~Tb}$ seconds. This means that the required bandwidth for QPSK is double to BPSK modulation, that is, $\mathrm{B}_{\mathrm{QPSK}}=0.5 \mathrm{~B}_{\mathrm{BPSK}}$. $\mathrm{BER}$ for $\mathrm{QPSK}$ can be described as:[15]

$$
\text { BER }_{\mathrm{QPSK}}=\operatorname{erfc}(\sqrt{ } \text { SNR })=\mathbf{2 B E R _ { \text { BPSK } }}
$$

\section{E. Pulse Amplitude Modulation}

The AM in pulse amplitude modulation (PAM) are fully real for $m=1,2 \ldots$, M. PAM-16 sends four bits in a single packet. It's a modulation system in which the signal is sampled at regular intervals, with each sample proportional to the signal's amplitude at the time of sampling [16]. There are 16 different symbols that can be used with 4 bits.

$$
\mathbf{B E R}_{\mathrm{PAM}}=\frac{1}{2} \operatorname{erfc}\left(\frac{\sqrt{S N R \log 2 M}}{2 \sqrt{2}(M-1)}\right)
$$

And the bit rate can be expressed as follows:

$$
\mathrm{R}_{\mathrm{b}}=\mathrm{B}_{\mathrm{req}} \log _{2} \mathrm{M}=\mathrm{B}_{\mathrm{req}} \mathrm{K}_{2}
$$

\section{STATISTICAL ATMOSPHERIC TURBULANCE MODELS}

\section{A. Lognormal Model}

Because of its ease of mathematical calculation, the lognormal distribution is a popular model for the probability density function of irradiance. To develop the negative exponential channel model in MATLAB, the random input bit pattern was generated at the transmitter end using the OOK (On-Off Keying) modulation technique. The pdf of the received optical field $\mathrm{I}$ is given as $\mathrm{f}$ using the lognormal distribution model (I)[17 and 18].

$$
\mathrm{f}(\mathrm{I})=\frac{1}{\sqrt{2 \pi \sigma^{2} I}} \exp \left[-\frac{\left(\ln (I)-m_{i}\right)^{2}}{2 \sigma_{i}^{2}}\right], \mathrm{I} \geq 0
$$

As turbulence strength rises, many scattering effects must be considered. Lognormal statistics demonstrate significant variations when compared to experimental data.

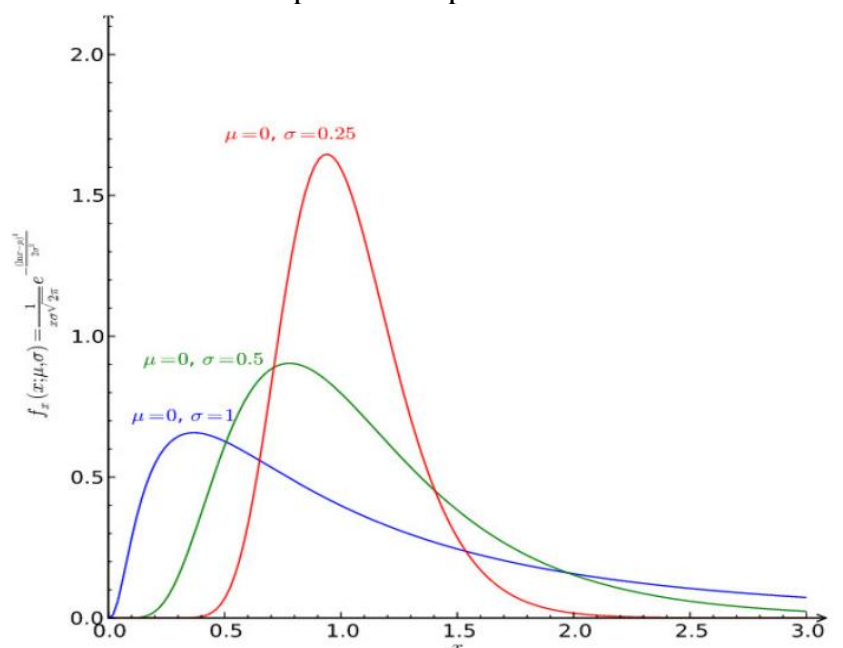

Fig.1. Lognormal distribution pdf [17]

SNR can be calculated by $\left\{4 R^{2} P^{2} /(\boldsymbol{\sigma} 1+\boldsymbol{\sigma} 0)^{2}\right\}$. Where, $\mathrm{R}$ is responsivity of the receiver, $\mathrm{P}$ is transmitted power and $\boldsymbol{\sigma} 1$ and $\boldsymbol{\sigma} 0$ are standard deviation of noise currents for symbols ' 1 ' and ' 0 '. Using this equation, SNR v/s. BER relationship can be plotted as shown:

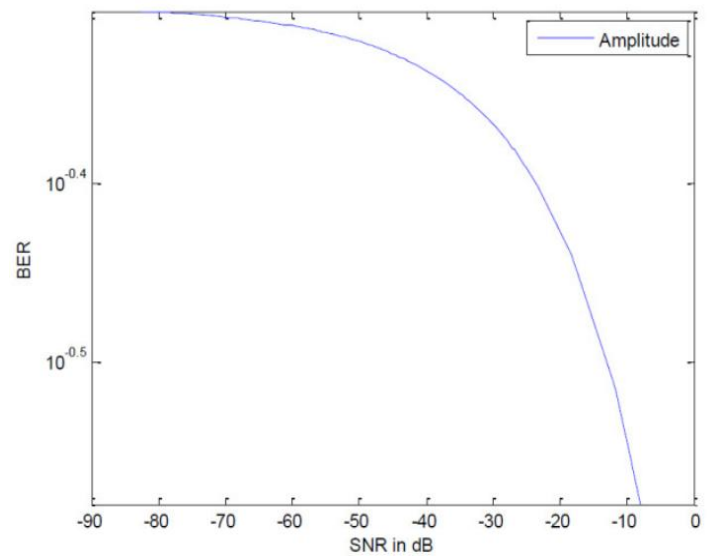

Fig.2. Lognormal distribution BER v/s. SNR curve. [17]

\section{B. Negative Exponential Model}

When irradiance changes are severe and the link length is several kilometres, the number of separate scatters increases dramatically [18].Signal amplitude follows a Rayleigh distribution in this case, resulting in a signal intensity with a negative exponential statistic (square of field amplitude): [19]

$$
\mathrm{p}(\mathrm{I})=\frac{1}{I_{0}} \exp \left(-\frac{I}{I_{0}}\right), \mathrm{I} \geq 0
$$

where $I o$ is the mean radiance (average photon count per slot). Here $\boldsymbol{\sigma}_{\mathrm{SI}}^{2}=1$ (or in the vicinity of 1 ).

Published By: Blue Eyes Intelligence Engineering and Sciences Publication

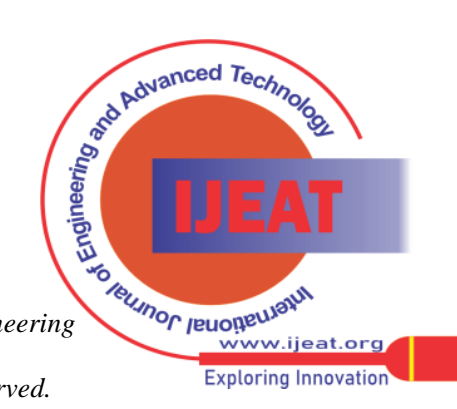




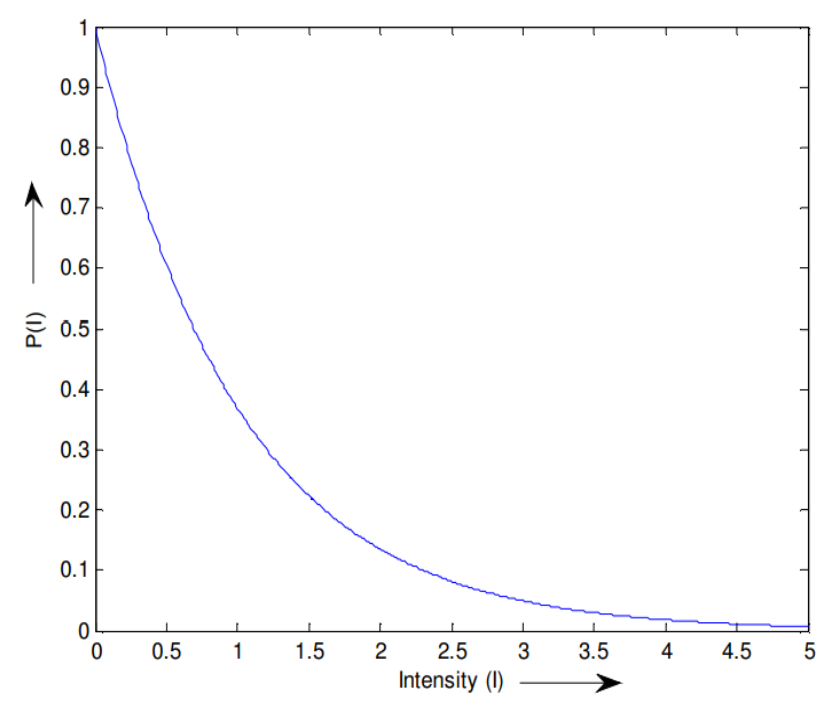

Fig.3. Negative Exponential Distribution pdf. [17]

The analysis of the negative exponential channel model was done in MATLAB and the BER vs. SNR curve was analyzed in it [20].

The equations used for finding out the BER and SNR are given below [19]:

$$
\begin{aligned}
& \text { Spontaneous SNR } \gamma=\frac{S}{N}=\frac{(\eta \mathrm{I})^{2}}{N o} \\
& \text { Average SNR } \mu=\frac{\text { Savg }}{N}=\frac{(\eta<\mathrm{I}>)^{2}}{N o}
\end{aligned}
$$

$$
\begin{aligned}
\text { Average BERPav } & =\int_{0}^{+\infty} P(I) f(I) d I \\
& =\frac{1}{2} \int_{0}^{+\infty} \operatorname{erfc}\left(\frac{(\eta I)}{2 \sqrt{N o}}\right) f(I) d I
\end{aligned}
$$

\section{SIMULATION AND DISCUSSION}

\section{A. Performance Analysis of Different Modulation} Schemes in AWGN Channel

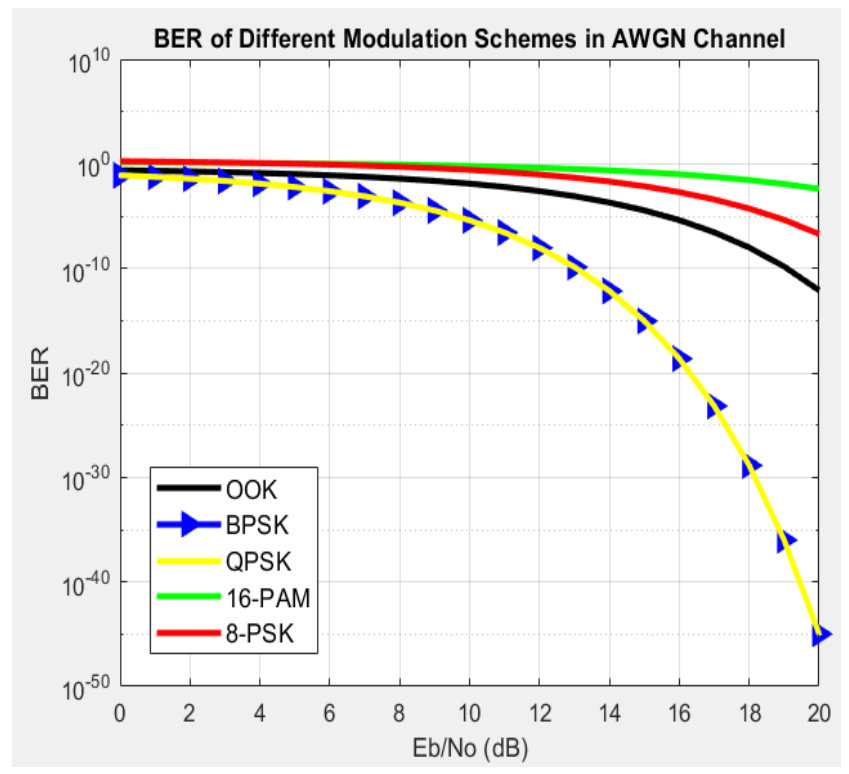

Fig.4.Comparison of $\mathbf{5}$ modulation schemes for BER

The BER versus SNR for various modulation schemes under AWGN Channel is given in Fig 4. As it is shown, the
BER performance for BPSK and QPSK are the same. Also, the required SNR of OOK is about " $5.07 \mathrm{~dB}$ " more than the required SNR of BPSK to obtain a desired BER performance.

The average power requirement by the QPSK is the same as BPSK, or only a few units more than BPSK. And in terms of BER, both are very close to each other. So, the BPSK/QPSK is preferred when no turbulence is taken into account by providing least Bit Error.

Following the analytical comparison, the simulation results show BER performance for OOK, 8-PSK, 16-PAM, BPSK, and QPSK modulation techniques. And the communication impairments such as scintillation and dispersion haven't been taken into account in the simulation.

\section{B. Performance Analysis of Different Modulation Schemes in LN Channel $\left(\sigma^{2}=0.36\right)$}

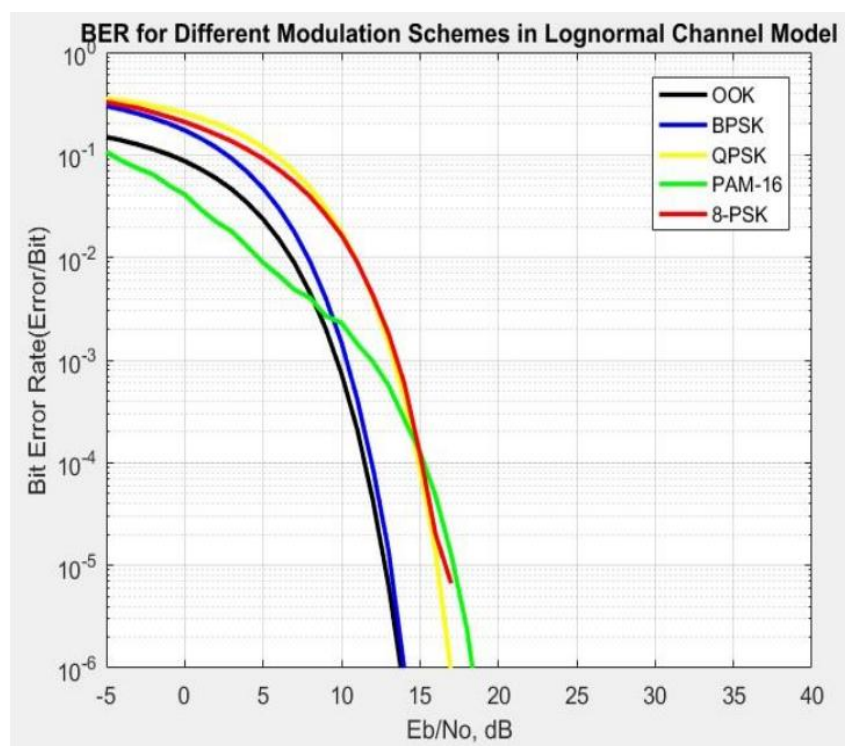

Fig. 5. Variation of BER versus SNR for various modulation techniques using Log-Normal Channel Model for log irradiance variance $\sigma_{1^{2}}=0.36$

The standard deviation parameter $\left(\boldsymbol{\sigma}_{\mathbf{l}}\right)$ was set to 0.6 in fig. 5 , resulting in log irradiance variance $\left(\sigma_{1}{ }^{2}\right)$ is 0.36 . This low value of $\boldsymbol{\sigma}_{1}{ }^{2}$ implies a lesser atmospheric turbulence and the value of BER is determined from atmospheric turbulence, thus a particular value of SNR it is expected to be low for all modulation techniques.

The comparison of alternative modulation strategies for weak atmospheric turbulence using the Log-Normal Model is shown in Fig. 6. It shows that when the log irradiance variance is 0.36 , BER is lowest for PAM-16 modulation at lower SNR values and highest for OOK at higher SNR values.

As a result, PAM-16 is favoured for lower SNR values $(<8 \mathrm{~dB})$ and simpler modulation techniques like OOK, BPSK is favoured for higher SNR values (8-20dB).

Published By:

Blue Eyes Intelligence Engineering and Sciences Publication

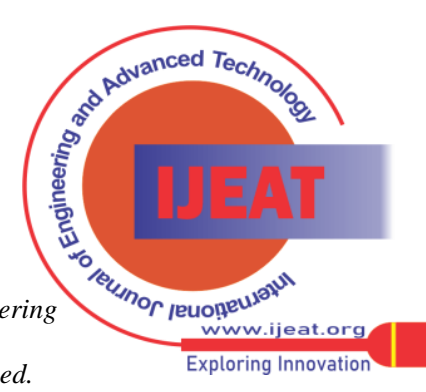


TABLE I COMPARISON BETWEEN DIFFERENT MODULATION TECHNIQUES FOR SNR= 5DB AND $\boldsymbol{\sigma}^{2}=0.36$ USING LOG-NORMAL CHANNEL MODEL

\begin{tabular}{|c|c|}
\hline Modulation & BER Values $\left(\times \mathbf{1 0}^{-\mathbf{3}}\right)$ \\
\hline PAM-16 & 8.92 \\
\hline OOK & 23.69 \\
\hline BPSK & 47.24 \\
\hline 8-PSK & 91.47 \\
\hline QPSK & 118.50 \\
\hline
\end{tabular}

TABLE II COMPARISON BETWEEN DIFFERENT MODUlATION TECHNIQUES FOR SNR= 13dB AND $\sigma^{2}=0.36$ USING LOG-NORMAL CHANNEL MODEL

\begin{tabular}{|c|c|}
\hline Modulation & BER Values $\left(\times \mathbf{1 0}^{-\mathbf{3}}\right)$ \\
\hline OOK & 0.0064 \\
\hline BPSK & 0.0140 \\
\hline PAM-16 & 0.5682 \\
\hline 8-PSK & 1.8130 \\
\hline QPSK & 1.8150 \\
\hline
\end{tabular}

C. Performance Analysis of Different Modulation Schemes in LN Channel $\left(\boldsymbol{\sigma}^{2}=\mathbf{0 . 5 6}\right)$

The value of log irradiance variance $\left(1^{2}\right)$ is increased to 0.56, and the Bit Error rate for all modulation schemes is likewise increased. As we know $\mathbf{l}^{2}$ is directly proportional to $\mathrm{C}_{\mathrm{n}}{ }^{2}$, as shown by equation:

$$
\mathbf{l}^{2}=1.23 C_{\mathrm{n}}^{2} \mathrm{k} 7 / 6 \mathrm{~L}_{\mathrm{p}}^{11 / 6}
$$

Where, wave number $k=2 /, L_{p}$ is horizontal distance of optical irradiance, $C_{\mathrm{n}}{ }^{2}$ is refractive index structure parameter and $\mathrm{I}^{2}$ is $\log$ irradiance variance.

The parameter $C_{\mathrm{n}}{ }^{2}$ (refractive index structure parameter) defines the amount of unevenness in the refractive index structure of the channel, which is responsible for deterioration of link.

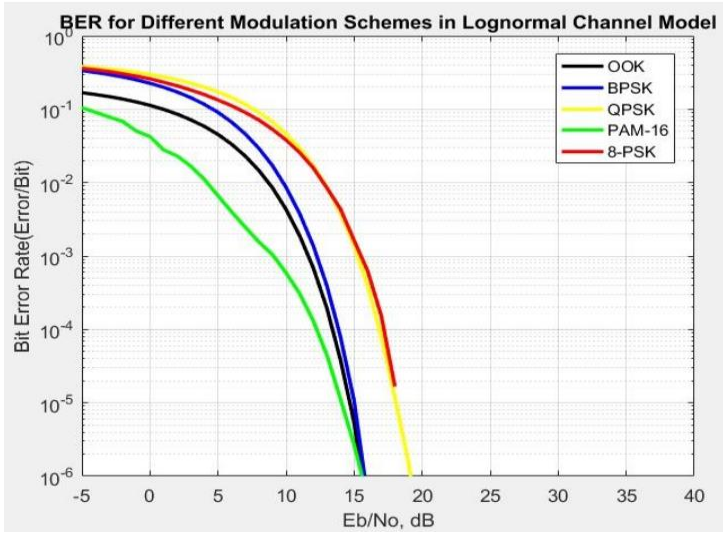

Fig. 6. Variation of BER versus SNR for various modulation techniques using Log-Normal Channel Model for $\log$ irradiance variance $\sigma_{1}^{2}=0.56$
The third plot, taken from fig. 6, has a log irradiance variance of 0.56 , indicating stronger air turbulence than the prior scenario. The BER values for PAM-16 is the lowest in this scenario for the whole range of SNR shown in tables III and IV.

TABLE III COMPARISON BETWEEN DIFFERENT MODULATION TECHNIQUES FOR SNR $=5$ dB AND $\sigma^{2}=0.56$ USING LOG-NORMAL CHANNEL MODEL

\begin{tabular}{|c|c|}
\hline Modulation & BER Values $\left(\times \mathbf{1 0}^{\mathbf{- 3}}\right)$ \\
\hline PAM-16 & 6.63 \\
\hline OOK & 45.41 \\
\hline BPSK & 90.70 \\
\hline 8-PSK & 133.40 \\
\hline QPSK & 172.10 \\
\hline
\end{tabular}

TABLE IV COMPARISON BETWEEN DIFFERENT MODULATION TECHNIQUES FOR SNR= 13dB AND $\sigma^{2}=0.56$ USING LOG-NORMAL CHANNEL MODEL

\begin{tabular}{|c|c|}
\hline Modulation & BER Values $\left(\times \mathbf{1 0}^{\mathbf{- 3}}\right)$ \\
\hline PAM-16 & 0.0449 \\
\hline OOK & 0.1950 \\
\hline BPSK & 0.3947 \\
\hline 8-PSK & 8.4870 \\
\hline QPSK & 8.7580 \\
\hline
\end{tabular}

D. Performance Analysis of Different Modulation Schemes in LN Channel $\left(\sigma^{2}=0.72\right)$

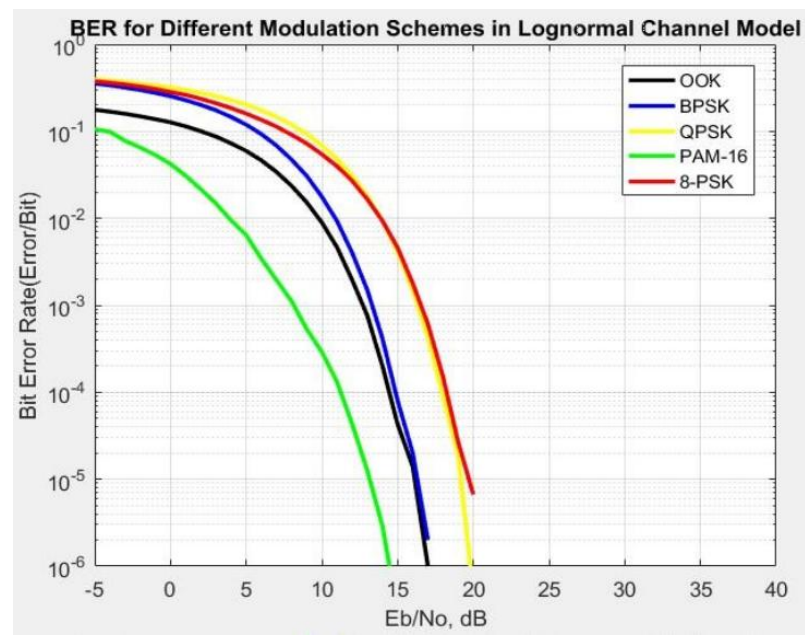

Fig. 7. Variation of BER versus SNR for various modulation techniquesusing Log-Normal Channel Model for $\log$ irradiance variance $\sigma_{1^{2}}=0.72$

Published By:

Blue Eyes Intelligence Engineering and Sciences Publication

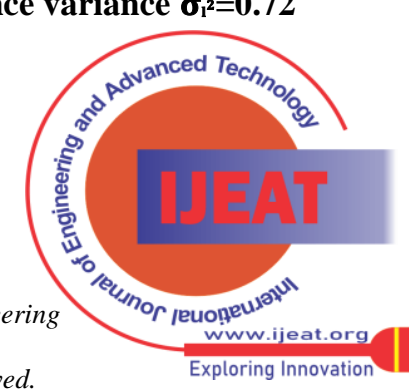


If log irradiance variance $\left(1^{2}\right)$ is increased to 0.72 , it can be visually deduced in plot 4 from Fig 8 that PAM16 has a much lower BER for the overall range of SNR ( -5 to $20 \mathrm{~dB}$ ). Tables $\mathrm{V}$ and VI show the BER values for variation as 0.72 at SNRs of $5 \mathrm{~dB}$ and $13 \mathrm{~dB}$, respectively.

TABLE V COMPARISON BETWEEN DIFFERENT MODULATION TECHNIQUES FOR SNR= 5dB AND $\boldsymbol{\sigma}^{2}=0.72$ USING LOG-NORMAL CHANNEL MODEL

\begin{tabular}{|c|c|}
\hline Modulation & BER Values $\left(\times \mathbf{1 0}^{-\mathbf{3}}\right)$ \\
\hline PAM-16 & 6.41 \\
\hline OOK & 59.49 \\
\hline BPSK & 119.40 \\
\hline 8-PSK & 159.80 \\
\hline QPSK & 202.40 \\
\hline
\end{tabular}

TABLE VI COMPARISON BETWEEN DIFFERENT MODULATION TECHNIQUES FOR SNR= 13dB AND $\boldsymbol{\sigma}^{2}=0.72$ USING LOG-NORMAL CHANNEL MODEL

\begin{tabular}{|c|c|}
\hline Modulation & BER Values $\left(\times \mathbf{1 0}^{-\mathbf{3}}\right)$ \\
\hline PAM-16 & 0.0013 \\
\hline OOK & 0.760 \\
\hline BPSK & 1.498 \\
\hline 8-PSK & 16.550 \\
\hline QPSK & 17.970 \\
\hline
\end{tabular}

\section{CONCLUSION}

Various modulation schemes have been analyzed in terms of their BER performance and the analysis has yielded the following conclusions:

- Under low values of log irradiance $\left(1^{2}\right)$ and high SNR conditions, OOK is preferred as they offer the least amount of BER.

- Under low values of log irradiance( $\left(^{2}\right)$ and low SNR conditions, it is best to use high data rate modulation schemes of 16-PAM as their BER levels will be negligibly low.

- As the value of $\mathrm{I}^{2}$ increases, indicating higher atmospheric disturbance, 16-PAM yields the least BER levels for any given SNR value.

- An adaptive modulation method, which varies between basic, low data rate and complicated, high data rate modulation techniques based on the SNR of the received signal, is recommended for maintaining a satisfactory data rate.

As a result, the above-mentioned comparison for modulation methods was effectively reviewed. The theoretical studies reveal that, when compared to other modulations such as OOK, BPSK, QPSK, PAM, and 8-PSK, only BPSK is the best performer in terms of BER, without any scintillation.

But in Log-Normal channel BER of 16-PAM was significantly better than other modulation schemes. The average BER performance of other modulation schemes show a direct drop after accounting for atmospheric changes. Experiments show that 16-PAM has good turbulence resistance properties under various turbulence settings.

\section{REFERENCES}

1. Upena Dalal, "Wireless Communications, Oxford Higher Education", 2009.

2. Rappaport, T.S, "Wireless Communications: Principles and Practice". IEEE Press, Piscataway (1996).

3. Z. Ghassemlooy and W. O. Popoola, Optical wireless communications system and channel modeling with MATLAB, CRC press Taylor and Francis group,New York, 2013.

4. F. A. Mahdavi and H. Samimi, "Performance Analysis of MIMO-FSO Communication Systems in Gamma-Gamma Turbulence Channels with Pointing Errors", 24th Iranian Conference on Electrical Engineering (ICEE), pp. 822-827, 2016.

5. H. Wu, B. Ciftcioglu and R. Berman, "Chip-scale demonstration of 3-D integrated intra-chip free-space optical interconnect", Proc. of SPIE. vol. 8265, pp. 82650C-1, 2012

6. K. Prabu, P. Paridhi Bharati, D. S. Kumar, "Performance Analysis of DPSK-SIM based FSO System over Strong Atmospheric Turbulence Channel", Annual IEEE India Conference (INDICON), pp. 1-4, 2013

7. X. Zhu and J. M. Kahn, "Free-space optical communication through atmospheric turbulence channels", IEEE Trans. Commun., vol. 50, no. 8, pp. 1293-1300, 2002.

8. https://ieeexplore.ieee.org/abstract/document/8244913

9. Gurpreet Kaur, Harmeet Singh, Amandeep Singh Sappal "Free Space Optical Using Different Modulation Techniques -A Review” International Journal of Engineering Trends and Technology (IJETT) -Volume-43 Number-2 -January 2017

10. L. ASH, DARRELL (1992). "A comparison between ook ask and fsk modulation techniques for radio links" (PDF). RF Monolithics. p. 6. Retrieved 24 February 2015.

11. Lloyd N. Trefethen, David Bau III, Numerical linear algebra, Philadelphia: Society for Industrial and Applied Mathematics, ISBN 978-0-89871-361-9, pp.56

12. Naresh Chand, Andrew J. Hunton, Bruce M. Eteson "A comparative study of $2.667 \mathrm{~Gb} / \mathrm{s}$ OOK, DPSK, and PPM modulation formats for FSO applications" Proc. SPIE 7091, Free-Space Laser Communications VIII, 70910G, 19 August 2008

13. Qi Lu, \& Qingchong Liu. (n.d.). Performance analysis for optical wireless communication systems using subcarrier psk intensity modulation through turbulent atmospheric channel. IEEE Global Telecommunications Conference, 2004. GLOBECOM '04.

14. M. Kumar, S. Tripathi, A. Vidyarathi, S. Mohanty and R. Gowri, "Various PSK modulation schemes for wireless communication," 2011 2nd International Conference on Computer and Communication Technology (ICCCT-2011), 2011, pp. 545-549, doi 10.1109/ICCCT.2011.6075129.

15. Zhang, F., Luo, Y., Wang, Y., Li, L., Zhu, L., Chen, Z., \& Wu, C. (2011). Experimental Comparison of Different BER Estimation Methods for Coherent Optical QPSK Transmission Systems. IEEE Photonics Technology Letters, 23(18), 1343-1345. doi:10.1109/lpt.2011.2160718

16. Barry J.R., Lee E.A., Messerschmitt D.G. (2004) Pulse-Amplitude Modulation. In: Digital Communication. Springer, Boston, MA.

17. Study of different atmospheric channel models, IJECET. ISSN 0976 - 6464(Print) ISSN 0976 - 6472(Online) Volume 5, Issue 1, January (2014), pp. 105-112. IAEME: www.iaeme.com/ijecet.asp Journal Impact Factor (2013): 5.8896 (Calculated by GISI).

18. Kamran Kiasaleh, "Performance of APD-Based, PPM free-space optical communication systems in atmospheric turbulence”. IEEE Transactions on Communications, vol. 53, pp.1455-1461, 2005.

Published By:

Blue Eyes Intelligence Engineering and Sciences Publication

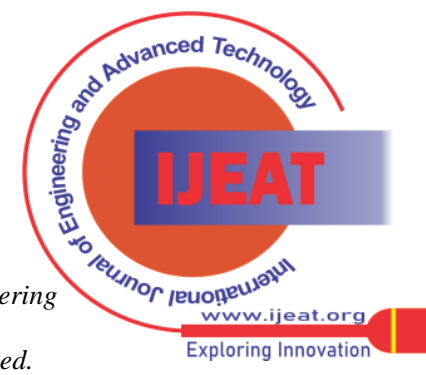


19. T. Ohtsuki, "Performance analysis of atmospheric optical PPM CDMA systems," J. Lightwave Technol., vol. 21, no. 2, pp. 406-411, Feb. 2003.

20. A. Al-Habash, L.C.Andrews and R.L.Phillips, "Mathematical model for the irradiance probability density function of a laser beam propagating through turbulent media", Opt. Eng., vol. 40, pp.1554-1562, 2001.

\section{AUTHORS PROFILE}

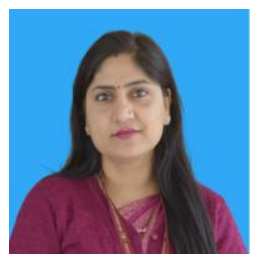

Dr. Priyanka Bhardwaj, has done her Ph.D and M.Tech from IIT Delhi and B.Tech Hons. as university ranker from UPTU. She is currently working as Associate Professor in ECE department with ABES Engineering College and leading Research and Innovation group of her department. She has got three patents and published more than 30 research articles in reputed Journals and Conferences. She has more than 13 years of academic and research experience and is reviewer of various Journals. Her area of interest is Optical Wireless, Nano photonics and Plasmonic. She has recently been felicitated by AICTE for her Excellence in Teaching and Research.

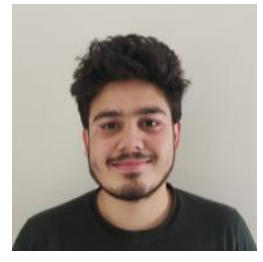

Aadi Jain, is in his final year of B.Tech in Electronics and Communication Engineering at Bharati Vidyapeeth's College of Engineering in New Delhi. He received a decent academic score in his 10+2 from a CBSE school. He is well-versed in embedded systems, the Internet of Things, and digital electronics. Control Systems and Embedded Systems are two of his areas of interest.

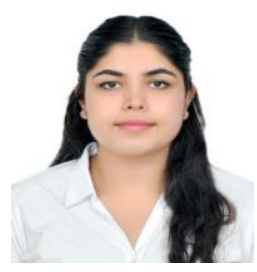

Manveen, is in her final year of B.Tech in Electronics and Communication Engineering at Bharati Vidyapeeth's College of Engineering in New Delhi. She is a creative Electronics Engineer with a strong background in telecommunications and electronics. She can follow the logic of electronic circuits and wireless communication using her analytical talents.

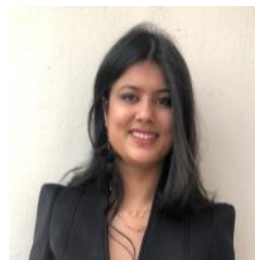

Richita Kamal, is a final-year B.Tech student in Electronics and Communication Engineering at Bharati Vidyapeeth's College of Engineering in New Delhi. She's a creative electronics engineer with a background in telecommunications and electronic devices. She knows how to route embedded circuits, measure resistance devices, and build effective circuit boards. She focuses on compact and portable electronics.

Rishab Chittlangia, is in his final year of B.Tech in Electronics and Communication Engineering at Bharati Vidyapeeth's College of Engineering in New Delhi. He has strong design and integration capabilities, as well as intuitive problem-solving abilities. He is enthusiastic about putting new concepts into action and getting them off the ground. He is capable at translating commercial needs into technical solutions.

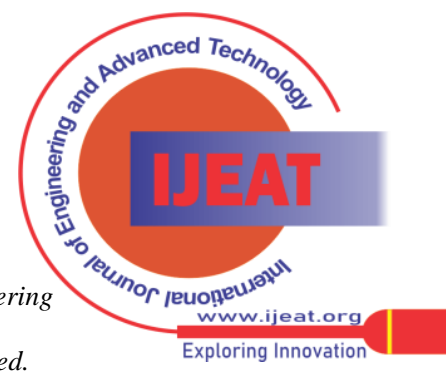

